ECCOMAS

Proceedia
COMPDYN 2021

$8^{\text {th }}$ ECCOMAS Thematic Conference on Computational Methods in Structural Dynamics and Earthquake Engineering

M. Papadrakakis, M. Fragiadakis (eds.)

\title{
DEVELOPMENT OF LOW COST SENSORS FOR MONITORING OF STRUCTURES
}

\author{
Giuseppe Maddaloni ${ }^{1}$, Alessandra De Angelis ${ }^{1}$, Francesco Minicozzi ${ }^{1}$, Claudio \\ Martino $^{2}$ and Maria R. Pecce ${ }^{1}$
}

1. Department of Engineering, University of Sannio

Piazza Roma 21, Benevento-Italy

e-mail: \{maddaloni, adeangelis, francesco.minicozzi, pecce\}@unisannio.it

2. Istituto Nazionale di Geofisica e Vulcanologia (INGV)

Osservatorio Vesuviano, via Diocleziano 328, Naples-Italy

e-mail: martino.claudio@gmail.com

\begin{abstract}
In the last years, in Italy, due to the recent catastrophic collapses, an increasing amount of resources has been invested in the maintenance of existing infrastructures. In particular, the monitoring of the structural "health" has assumed a crucial role in the assessment of structures and infrastructures. The technological advancement obtained in the field of informatics and electronic has allowed to move from a discrete and partial control of the structural conditions to a continuous and complete Structural Health Monitoring (SHM). Different techniques may be applied and the Operational Modal Analysis (OMA), among others, aims at identifying the health status of the structure by the modal properties when is under its operating conditions. This paper compares the results of OMA technique using the vibration data obtained by two different sensors equipment applied to an existing bridge located in Benevento, Italy. A dynamic test was performed in 2020 by using a low cost experimental equipment specially designed and developed by the University of Sannio. The tests results have been compared with the data obtained on the same bridge in 2018 by using a commercial and more expensive sensors equipment. The main purpose of the comparison is to support the "homemade" equipment development identifying the aspects on which to improve the same.
\end{abstract}

Keywords: SHM, OMA, low cost sensors, data processing. 


\section{INTRODUCTION}

A large number of road infrastructures has widely overcome 50 years of service design life and need urgent prevention and control measures. Following the critical events occurred in the last years to several highway infrastructures, the issue of their maintenance has assumed a primary role [1]. The interest is very significant since they are not single punctual elements but are part of a more extensive network. Hence, the potential disruption could have exceptional consequences in both the economic and social sides, proportionally to the importance of the infrastructure itself. Structural damage depends on several elements as, among others, quality and type of materials, age, construction techniques, loads level and environmental conditions. Generally, degradation or damaging phenomena can be responsible to modify the mechanical properties of the materials [2]. In reinforced concrete elements, the corrosion of the steel bars is the main cause of degradation phenomena. Due to the porosity of concrete, some chemicals including carbon dioxide, oxygen and water, can penetrate the material triggering the carbonation process. Chloride ions, if passing a critical concentration threshold [3], perforate the protective oxide film surrounding the rebars, starting the corrosion phenomena. The latter case is typical of bridges that are subjected to winter frosts and are generally kept operational using de-icing salts. The same is true for all those structures located in coastal areas or directly exposed to seawater [4].

From here, the necessity of checking the "structures health" by using effective monitoring systems. The most appropriate monitoring system depends on many factors. Traditional checking and monitoring methods for infrastructures rely on visual inspections, but they often lead to a temporary interruption of use and must be carried out by highly qualified personnel. Furthermore, mainly due to the subjectivity of the evaluation, it is difficult, using this technique, to obtain an effective monitoring over time [5]. Hence, with the main target to provide automatic tools useful for observing the evolution of degradation phenomena in support of traditional techniques, many others elaborate methods were developed [6,7]. When the devices that allow the loading and damaging condition of a structure to be recorded, analyzed, localized and predicted, become an integral part of the structure, the monitoring approach is called Structural Health Monitoring (SHM) [8]. The SHM is a process based on a series of axioms [9] and phases [10] widely applied in various engineering sectors due to its ability to respond to adverse structural changes, improving structural reliability and life cycle management. To implement a SHM system, several components, such as sensors, data acquisition, transmission system and software for data processing, are needed. By analyzing data collected from sensors, it is possible to identify any damaging in progress and evaluate the structural performance both in operating and in exceptional (e.g. earthquakes or after earthquakes) conditions. The number of sensors to use depends on the structural dimension. For long structure as a bridge, it can represent a very expansive cost. For this reason, the development of low cost and easy to install sensors can be a fundamental target in the SHM applications. This work shows the results obtained by applying a network of nine prototype accelerometer sensors with these characteristics to an existing RC bridge located in south Italy. 


\section{OPERATIONAL MODAL ANALYSIS}

The dynamic behavior of a structure depends on mass, stiffness, damping and nevertheless by external and internal constraints. These properties give information about the free vibration response, therefore, if they do not change (e.g., as a result of structural damages), the dynamic characteristics remain the same. Generally speaking, the analysis of the dynamic behavior of a structure can be addressed using analytical or experimental approaches. For bridges, the most used technique in experimental approaches is the Operational Modal Analysis (OMA). It allows to identify the modal parameters of the structures $[11,12,13]$ based on vibration data collected when the structure is under its operating conditions, i.e., vehicular traffic, wind, etc. It relies on a series of basic assumptions such as linearity, stationarity, observability [14, 15]. OMA test is a suitable technique for SHM because interruption of the structure use is not required. Sensors can be permanently installed to identify changes in the dynamic properties. On the other hand, unknown load conditions can make it more difficult for the processing phase.

Over the last few decades, several mathematical methods have been developed to determine the modal parameters of the structure by OMA methodology (time or frequency domain, SDOF or MDOF methods, etc.).

In frequency domain, the Frequency Domain Decomposition (FDD) consists of the identification of the peaks of the Power Spectral Density (PSD) matrix of output. The basic assumption is that the resonance response is dominated by the contribution of the mode whose natural frequency is closest [16]. The contribute of the other modes is negligible, and therefore, FDD is classified as SDOF method. This method gives good results for structures having wellseparated modes and with non-negligible damping. FDD method relies on the Singular Value Decomposition (SVD) of the PSD matrix at a specific frequency $f$ [17] and allows to define resonance frequencies and mode shapes, but not modal damping. Modal damping ratio can be found by using the so-called Enhanced Frequency Domain Decomposition (EFDD) method. It is an improvement of the FDD method that uses the singular vector defined in FDD application but relies on the so-called Modal Assurance Criterion (MAC) that allow to compare the modes shape $\left\{\phi_{r}\right\}$. The MAC number is defined as:

$$
\operatorname{MAC}\left(\left\{u_{j}\right\} ;\left\{\phi_{r}\right\}\right)=\frac{\left|\left\{u_{j}\right\}^{H}\left\{\phi_{r}\right\}\right|^{2}}{\left(\left\{u_{j}\right\}^{H}\left\{u_{j}\right\}\right)\left(\left\{\phi_{r}\right\}^{H}\left\{\phi_{r}\right\}\right)}
$$

where $\left\{u_{j}\right\}$ is the generic singular vector closed to the peak response corresponding to the r-th mode $\left\{\varnothing_{r}\right\}$ and $H$ is the symbol to indicates the conjugate and transpose operator. MAC is a useful statistical indicator for the quantitative comparison between modal vectors. It ranges between 0 , namely the modes are completely unrelated and 1 which means that the modes perfectly match [18]. Finally, the Curve-Fitting Frequency Domain Decomposition (CFDD) is a parametric technique that relies on the curve-fitting of the PSD function in the frequency domain. Consequently, a more accurate estimation of frequencies and damping ratios is obtained [19].

Time-domain methods are based on the analysis of time histories or correlation functions. The most used is the Stochastic Subspace Identification (SSI) which most common declinations are the Unweighted Principal Component (SSI-UPC) and the Principal Component (SSI-PC). The difference between the SSI approaches is the weight matrixes to use for the determination of the observability matrix. Indeed, in SSI method the projection of the future unto the past (respectively the lower and the upper part of the Block Hankel matrix) defines a matrix so called "O" which columns represent a stacked free decay of the system to a set of unknown initial conditions. Since the observability matrix is unknown it is necessary to pre and post-multiply the matrix $\mathrm{O}$ by the so-called weight matrixes and then to apply the SVD to it [20]. 


\section{THE CASE STUDY}

The results of OMA technique using the vibration data obtained by two different experimental sensors equipment applied to an existing bridge located in Benevento (Italy), are herein proposed and compared. The case study is the so-called San Nicola Bridge, located in Benevento as part of the main street S.S. 90 bis and spans river San Nicola (Figure 1).

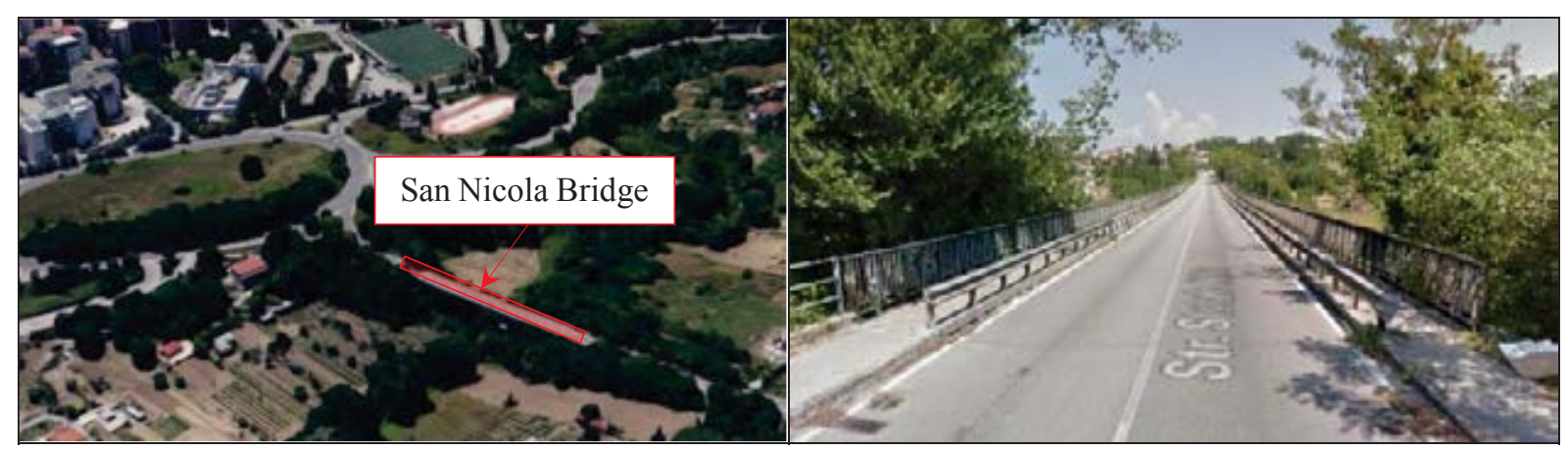

Figure 1 - San Nicola Bridge. Global (left) and street (right) views

The bridge was designed by the famous engineer Riccardo Morandi between 1952 and 1955 and built between 1955 and 1956. The static scheme is a portal frame composed by one main span $80.0 \mathrm{~m}$ long and two cantilevers of $20.0 \mathrm{~m}$ (Figure 2). The deck consists of four prestressed box-girders, whose webs vary in thickness, from a minimum of $13 \mathrm{~cm}$ at the midspan, to a maximum of $30 \mathrm{~cm}$ at the supports, and it is supported by two piers $9.40 \mathrm{~m}$ high and linked to the foundations underneath by hinges made of steel rebars. Each pier consists of eight columns of rectangular section, $40.0 \mathrm{~cm}$ thick and variable width from $1.50 \mathrm{~m}$ at the base to $4.00 \mathrm{~m}$ at the top, that are connected at the base and top by a transverse beam. The width of the upper slab is $9.00 \mathrm{~m}$ and consists of two traffic lanes, $7.00 \mathrm{~m}$ width, and two sidewalks $1.00 \mathrm{~m}$ width on both sides. Plan and prospectus of the bridge are reported in Figure 3.

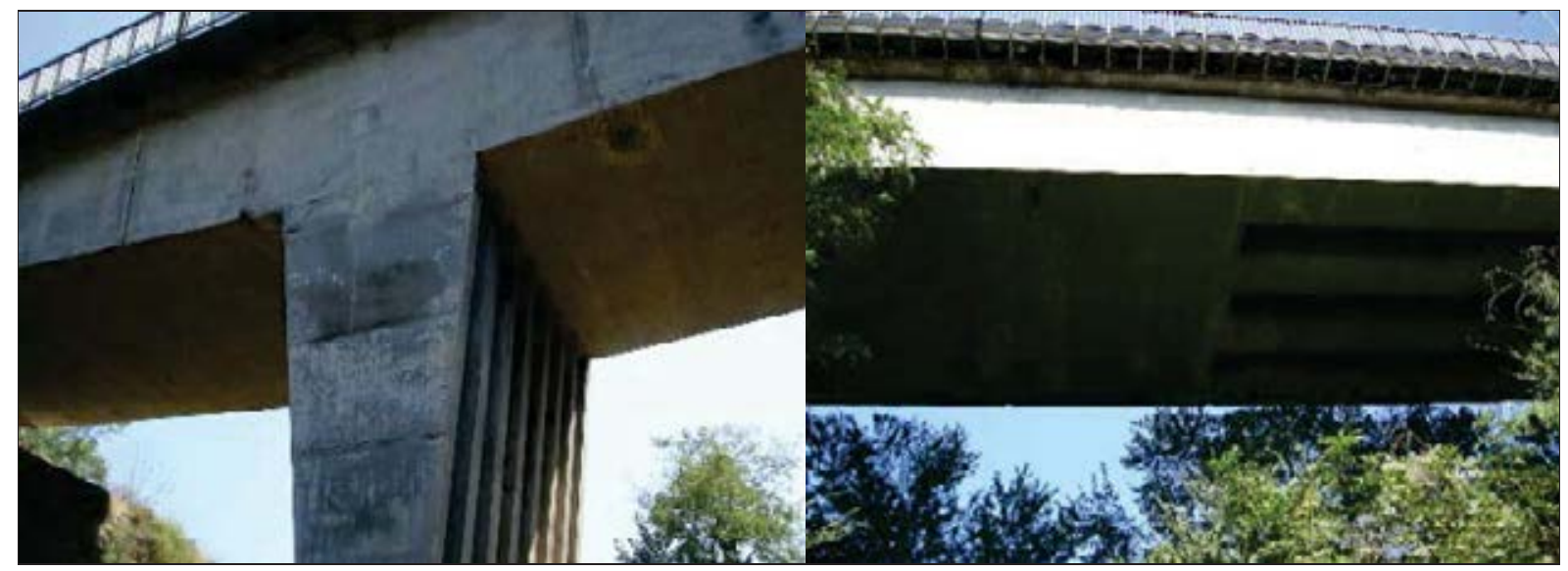

Figure 2 - Bridge pier (left), bridge deck (right) 


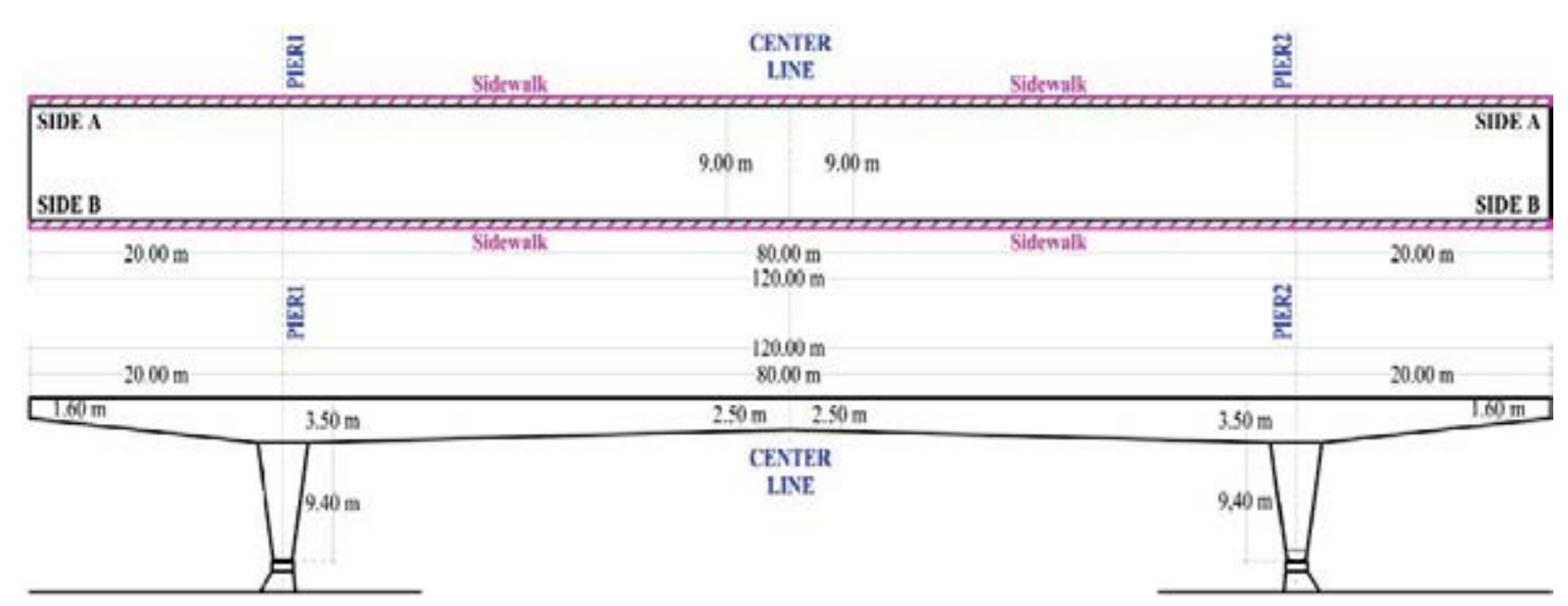

Figure 3 - San Nicola bridge plan and prospectus view

Following the collapse of the Polcevera viaduct (designed by the same engineer Riccardo Morandi) occurs in Genoa (Italy) on 14 August 2018, the bridge was closed as a preventive measure from August to December 2018. To determine the health status of the bridge, a series of tests were carried out by the Department of Engineering of the University of Sannio. In particular, a dynamic test to identify fundamental frequencies and mode shapes of the bridge was performed in 2018 and subsequently replicate in 2020. A finite element model has been also developed by CSiBridge software [21] using shell elements for the deck, frame elements for the piers and modelling the prestressing cables as tendon. Model calibration using the results coming from the experimental campaign was performed in [22]. Modal analysis results are reported in Figure 4. As evident, the first mode is transversal, with frequency $1.91 \mathrm{~Hz}$, the second vertical $(2.16 \mathrm{~Hz})$ and the third torsional $(4.16 \mathrm{~Hz})$.

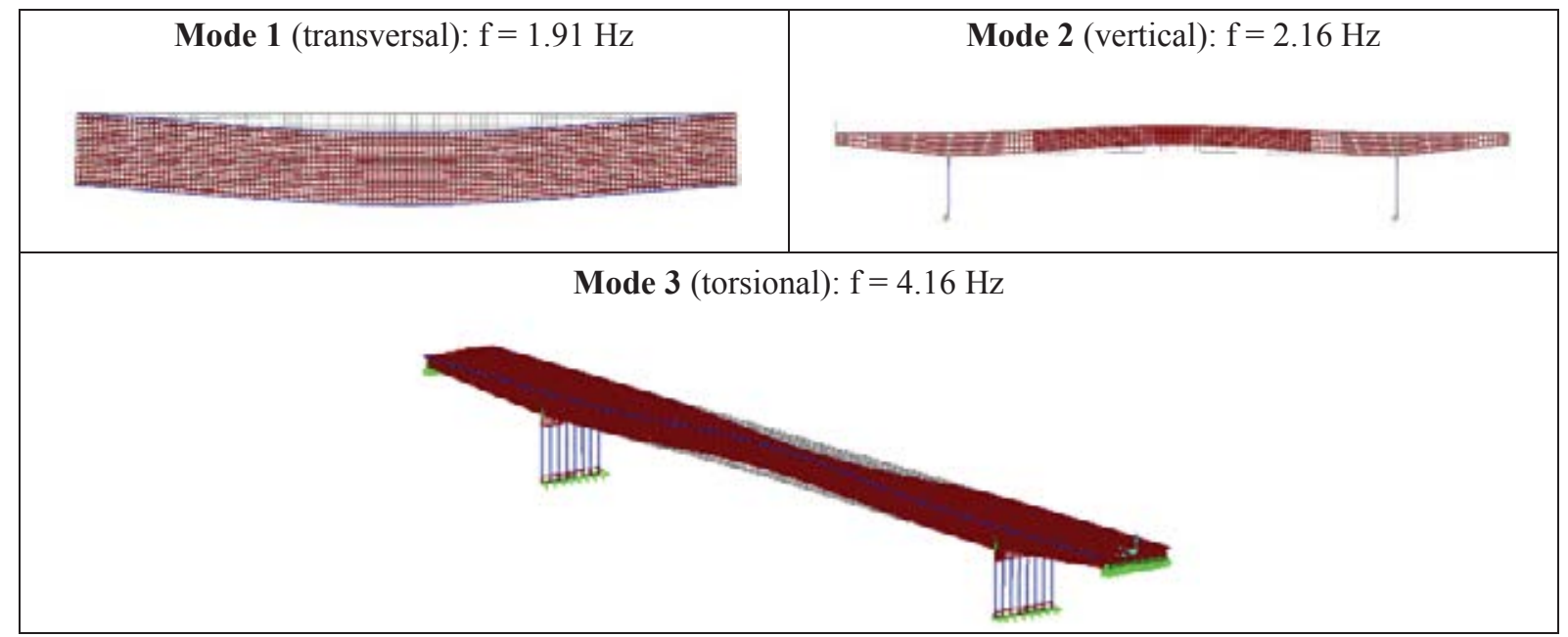

Figure 4 -Mode shapes and frequencies analysis results 


\section{EXPERIMENTAL TESTS DESCRIPTION}

In 2018 and 2020, dynamic tests were performed on San Nicola Bridge by using a commercial and prototype experimental equipment respectively. For safety, in both cases the bridge was closed to traffic, that means vibrations were caused just by environmental noise. The recorded row data have been pre-processed by filtering and resampling operations by MATLAB [23] and subsequently analyzed by the specific software ARTeMIS [24] to find the modal parameters of the structure.

In particular, on December 2018, the test was performed by the commercial and certified equipment of SEQUOIA manufacturing [25]. The system consists of a network of five sensors (called GEA II sensor) connected by cables to a data acquisition device (DAQ) (Figure 5). Designed to permanent or semi-permanent installations, its size is about $60 \times 30 \times 40 \mathrm{~cm}$ for the DAQ device and about $11 \mathrm{~cm}$ of diameter for the sensors (Figure 5). The commercial cost of the equipment is about 50'000 euros.

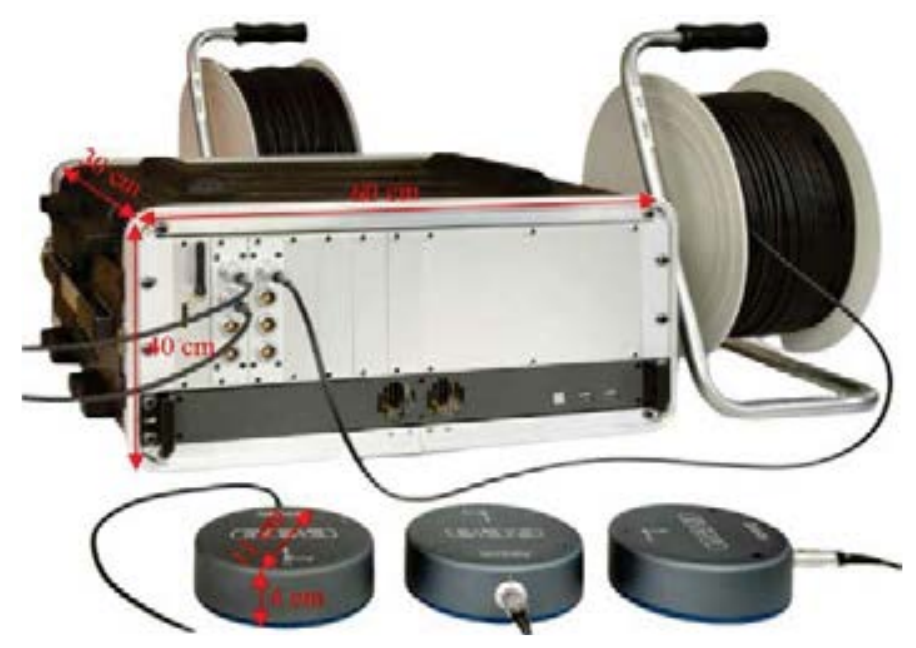

Figure 5 - GEA II sensors and DAQ

On September 2020, the dynamic test on the same bridge has been replicated by a prototype low-cost and no wired system (Figure 6) called SENTINEL properly developed by the Department of Engineering of the University of Sannio. The system consisted of a network of nine high sensitivity accelerometers capable to record structural vibrations. No data acquisition (DAQ) has been used: each device already has on board all that is needed to be an independent accelerometric station. The devices allow to set specific technical parameters as the sampling frequency (choosing between 125, 250, 500 and $1000 \mathrm{~Hz}$ ), the full-scale range (choosing between 1, 2, 4 and $8 \mathrm{~g}$ ), the file duration recording (the interval of data storing). The sensors are equipped with an internal battery, a micro-sd card slot, a router UMTS/WIFI, a GPS receiver, a microprocessor and a MEMS accelerometer (Figure 7). An autonomy of 24 hours recording time is guaranteed. The small size $(21 \times 15 \times 7 \mathrm{~cm})$ and the low weight (about $2 \mathrm{~kg}$ ) of the device makes it very easy to manage. The assumed commercial cost for each prototype device is about 500 euros (a total cost equipment of about 5'000 euros is estimated). 


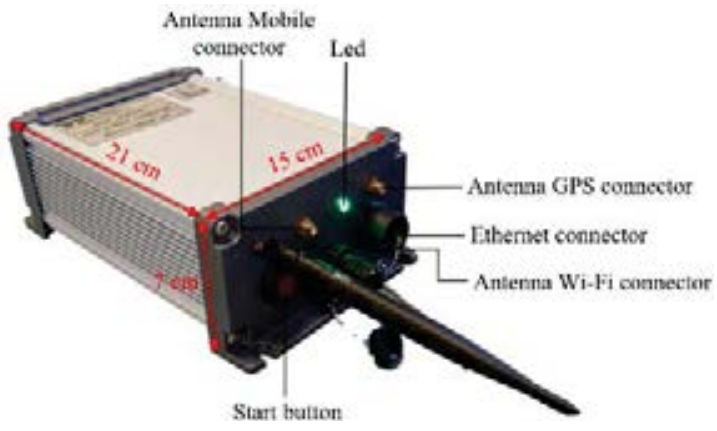

Figure 6-SENTINEL device
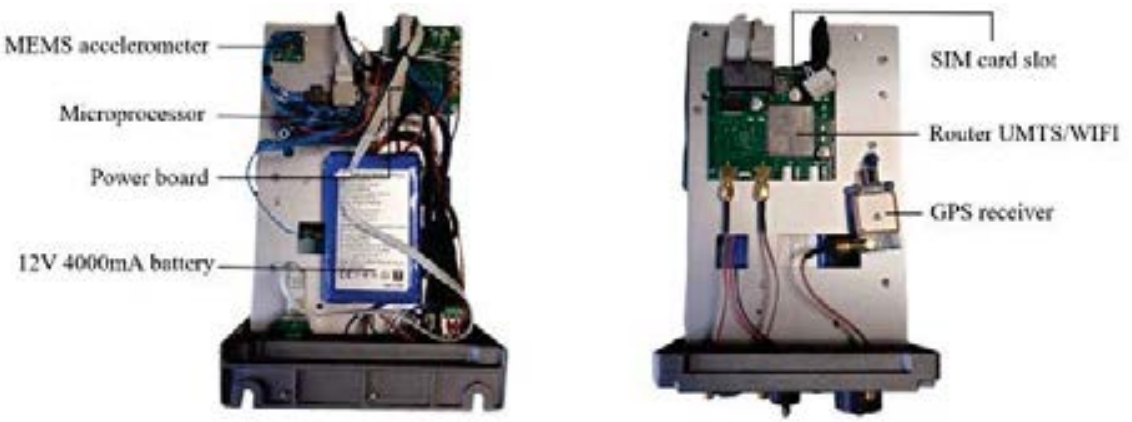

Figure 7 - SENTINEL device components

The devices have been fixed to the deck of the bridge by two screws (Figure 8). Three different setups were performed modifying their position except for the reference sensor (R) that remained in the same position for the entire experimental campaign. In Figure 9, the position of the sensors for each setup is reported. To note that $\mathrm{S}$ means sensor, the first number indicates the setup, the second the id of the sensor; the reference sensor is identified by the letter $\mathrm{R}$. The total number of the recorded points is 25 . The spacing among sensor positions is from a minimum of 6 to a maximum of 12 meters for both sides of the bridge (A and B).

The signals have been recorded for 30 minutes for each setup at $125 \mathrm{~Hz}$ sampling rate.

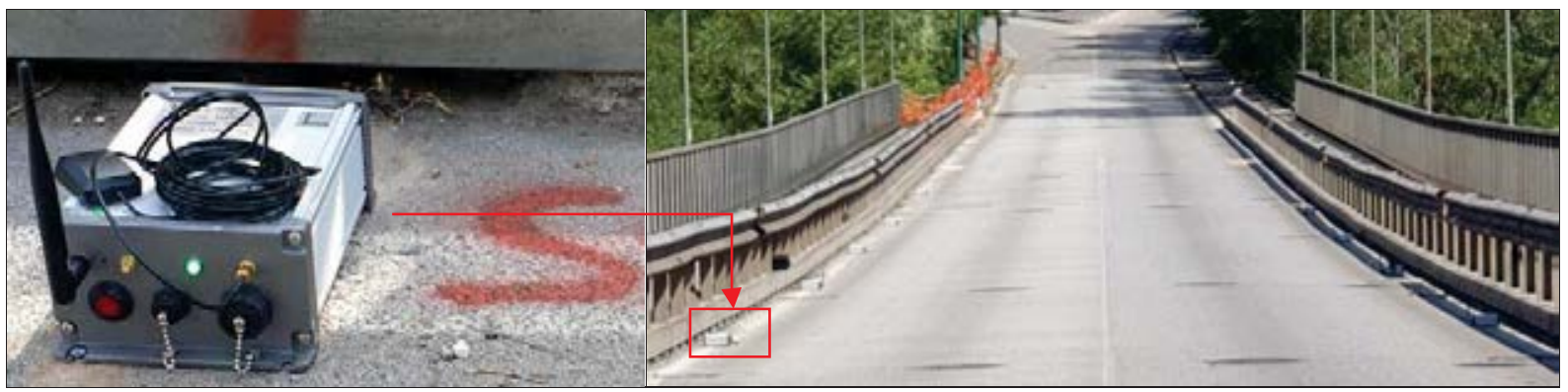

Figure 8 - Installation: device detail (left) and global view (right)

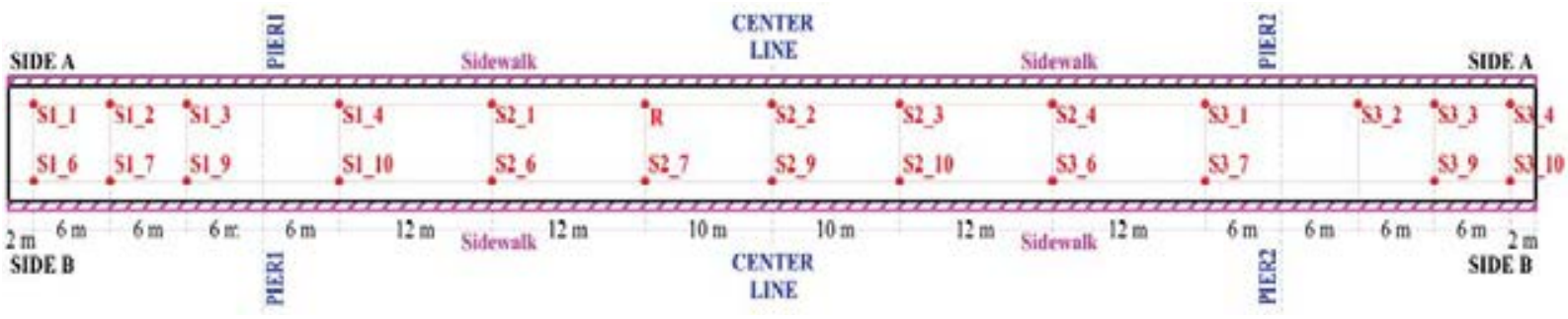

Figure 9 - Position of sensors for each setup in the 2020 experimental campaign 


\section{RESULTS OF THE EXPERIMENTAL CAMPAIGN USING PROTOTYPE EQUIPMENT}

The dynamic characteristics of the bridge obtained by the experimental campaign performed in 2020 using the prototype equipment have been evaluated by the software ARTeMIS. In particular, the mode shapes associated with the first two modes (transversal and vertical modes respectively), obtained applying the FDD method and normalize to one magnitude, are represented in Figures 10 and 11 for both sides A and B of the bridge separately. The black and the red continues lines, indicated the undeformed and the mode shapes respectively. Specifically, mode shapes represented by the dashed red lines are the first result of the row data elaboration. As evident the mode shapes are not clearly defined that is are not well-separated from each others. This is due to the absence of a DAQ device with the specific assignment to synchronize starting record of a system with multiply measure points. This problem has been partially solved by knowing the instant of time at which the last sensor has started the recording and manually cutting all the data stored by the other stations before this time. Furthermore, due to hardware problems, the sampling frequency was not constant. Specifically, even if the sampling rate has been set the same for all devices (i.e. $125 \mathrm{~Hz}$ ), the effective values have been different. Hence a resampling has been applied. The new mode shapes obtained after the synchronization procedure are represented as red continue lines in Figures 10 and 11. As evident, a good improvement was obtained for the first mode (transversal), especially for side A. Some discrepancies are still present at side B, that is two vectors have an opposite direction than expected (Figure 10). The same good results were found for the second modal (vertical) shape for side B while for side A some vectors have an unexpected direction (Figure 11).

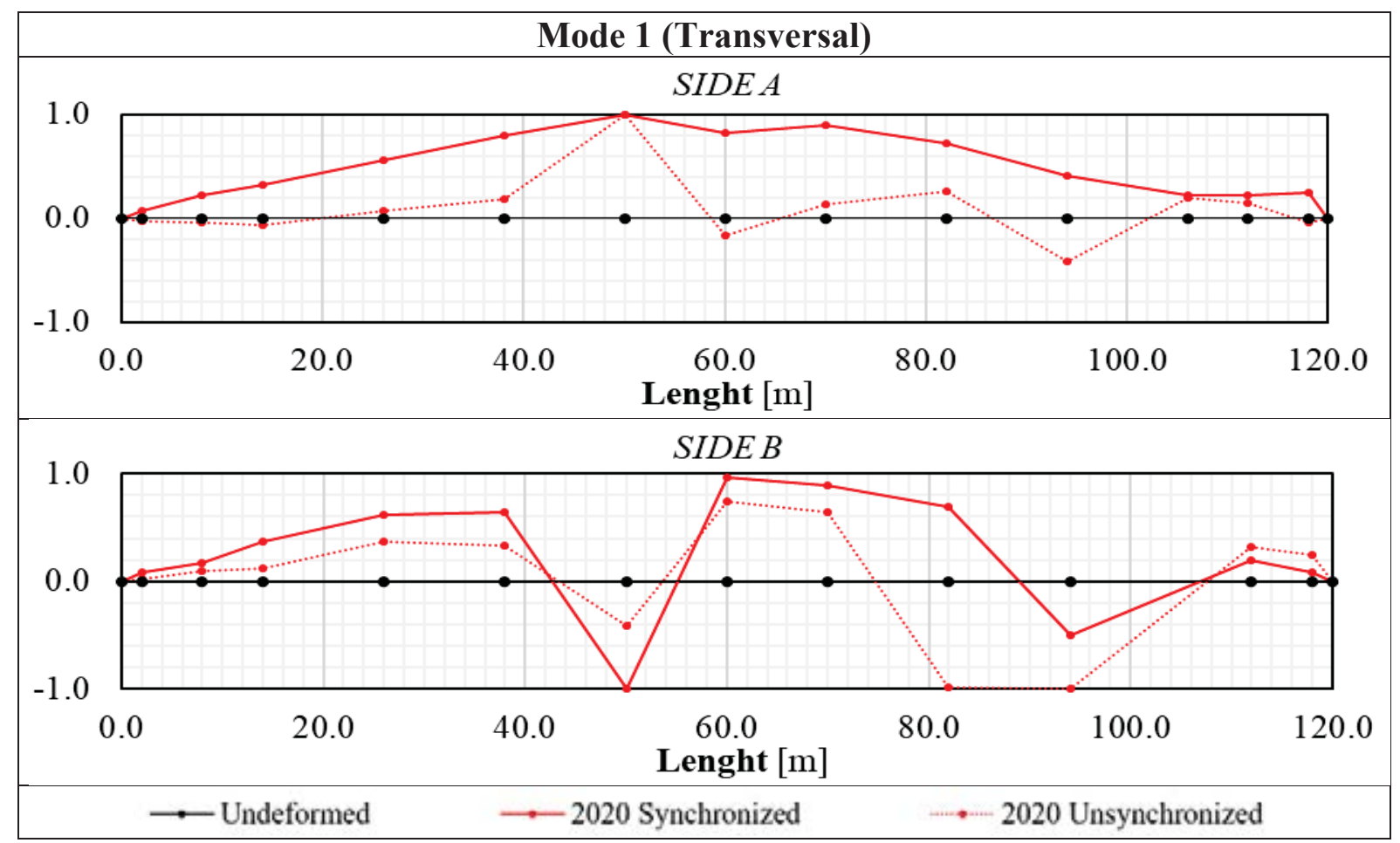

Figure 10 - Mode 1 (transversal): Comparison between unsynchronized (dashed red line) and synchronized (red line) mode shapes obtained applying FDD method 


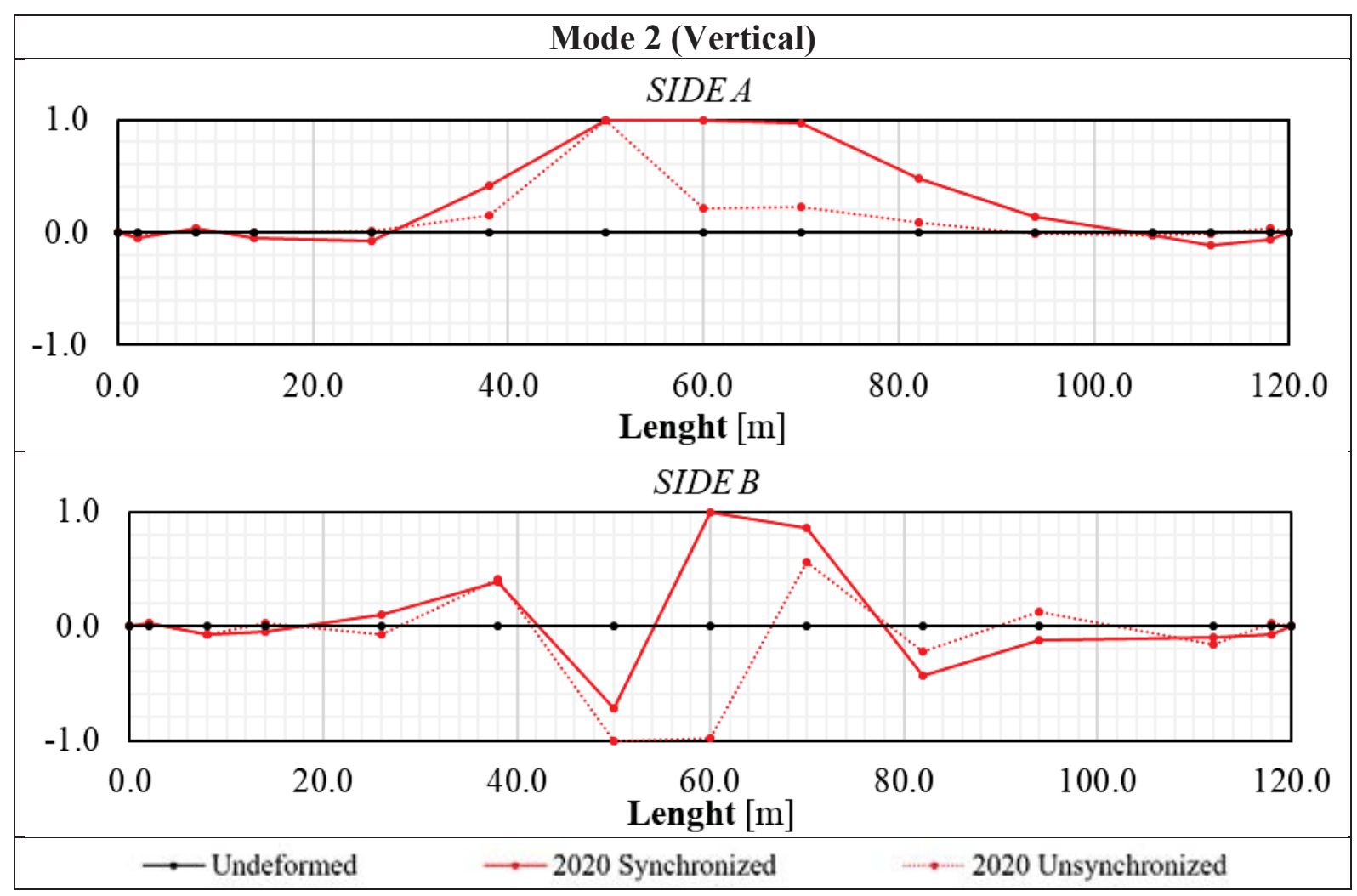

Figure 11 - Mode 2 (vertical): comparison between unsynchronized (dashed red line) and synchronized (red line) mode shapes obtained applying FDD method

For different frequency-domain methods applied (FDD, EFDD, CFDD), transversal mode frequency values are very similar $(1.26,1.27$ and $1.26 \mathrm{~Hz}$ respectively) and closed to analytical result $(1.91 \mathrm{~Hz})$. However, applying time-domain methods no transversal mode have been founded. A maximum difference about $10 \%$ has been obtained for frequency values associated with the vertical mode $(2.23-2.45 \mathrm{~Hz})$. Finally, frequency values related to the torsional mode show modest difference $(5.23-5.65 \mathrm{~Hz})$ but are quite far from analytical value $(4.16 \mathrm{~Hz})$. Table 1 summarizes these results.

\begin{tabular}{|c|c|c|c|}
\hline OMA method & $\begin{array}{c}\text { Mode 1 } \\
\text { (transversal) }\end{array}$ & $\begin{array}{c}\text { Mode 2 } \\
\text { (vertical) }\end{array}$ & $\begin{array}{c}\text { Mode 3 } \\
\text { (torsional) }\end{array}$ \\
\hline$F D D[\mathrm{~Hz}]$ & 1.26 & 2.23 & 5.46 \\
\hline$E F D D[\mathrm{~Hz}]$ & 1.27 & 2.23 & 5.46 \\
\hline$C F D D[\mathrm{~Hz}]$ & 1.26 & 2.22 & 5.46 \\
\hline$S S I-U P C[\mathrm{~Hz}]$ & - & 2.37 & 5.24 \\
\hline$S S I-P C[\mathrm{~Hz}]$ & - & 2.45 & 5.23 \\
\hline Max variation $[\%]$ & $\mathbf{0 . 0 8}$ & $\mathbf{1 0 . 1 6}$ & $\mathbf{4 . 3 8}$ \\
\hline Analytical results $[\mathrm{Hz}]$ & 1.91 & 2.16 & 4.16 \\
\hline
\end{tabular}

Table 1 - Results of 2020 experimental campaign in terms of frequencies 
Modal forms obtained using frequency domain (FDD, EFDD, CFDD) and time domain (SSI-UPC, SSI-PC) methods are compared in Figures 12 and 13. As shown, all the methods have given, as first mode, the same results. Small differences were found in the vertical mode. For the third mode, as expected, the methods failed to provide a unique solution.

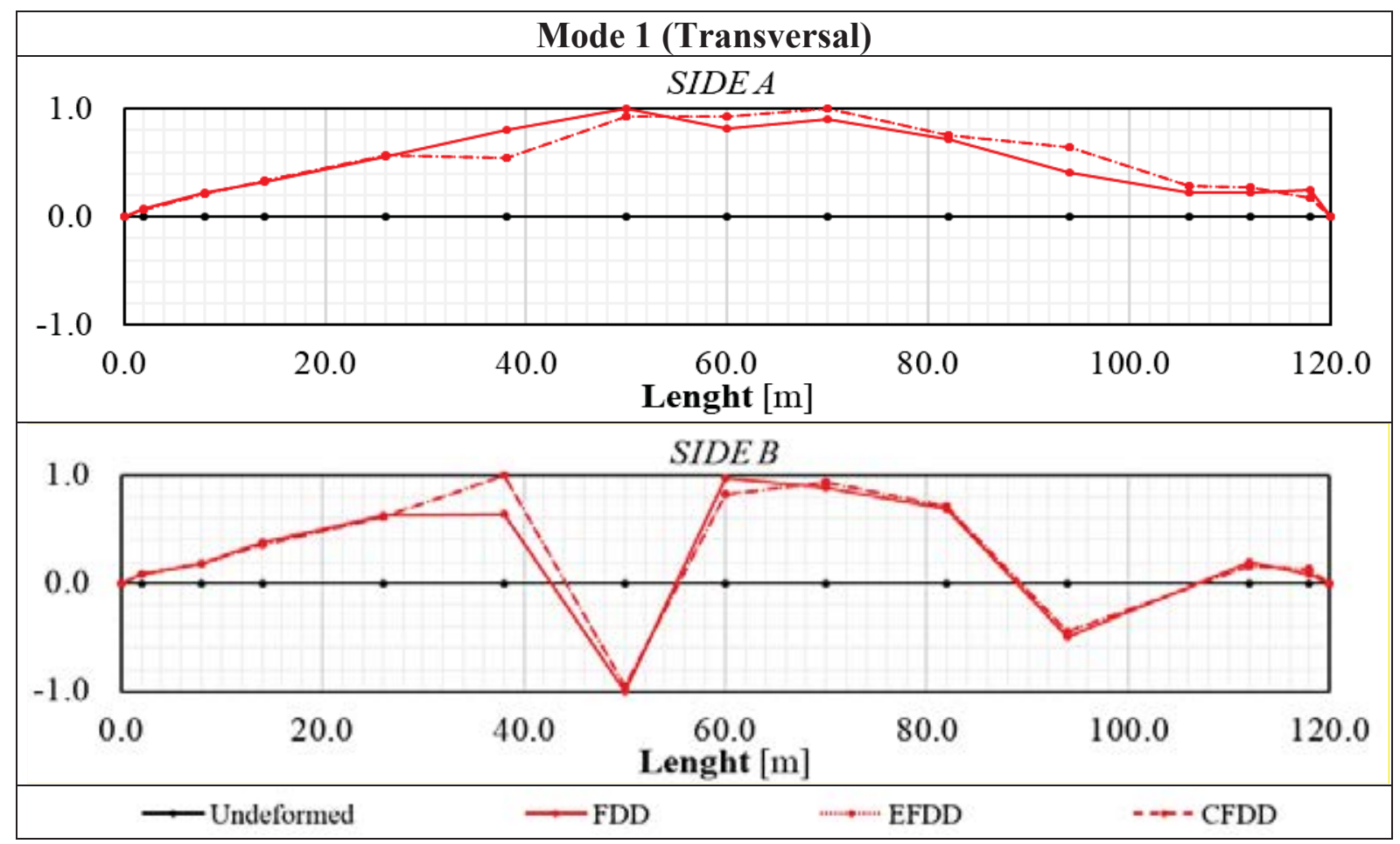

Figure 12 - Mode 1 (transversal): comparison of mode shapes obtained applying different OMA methods

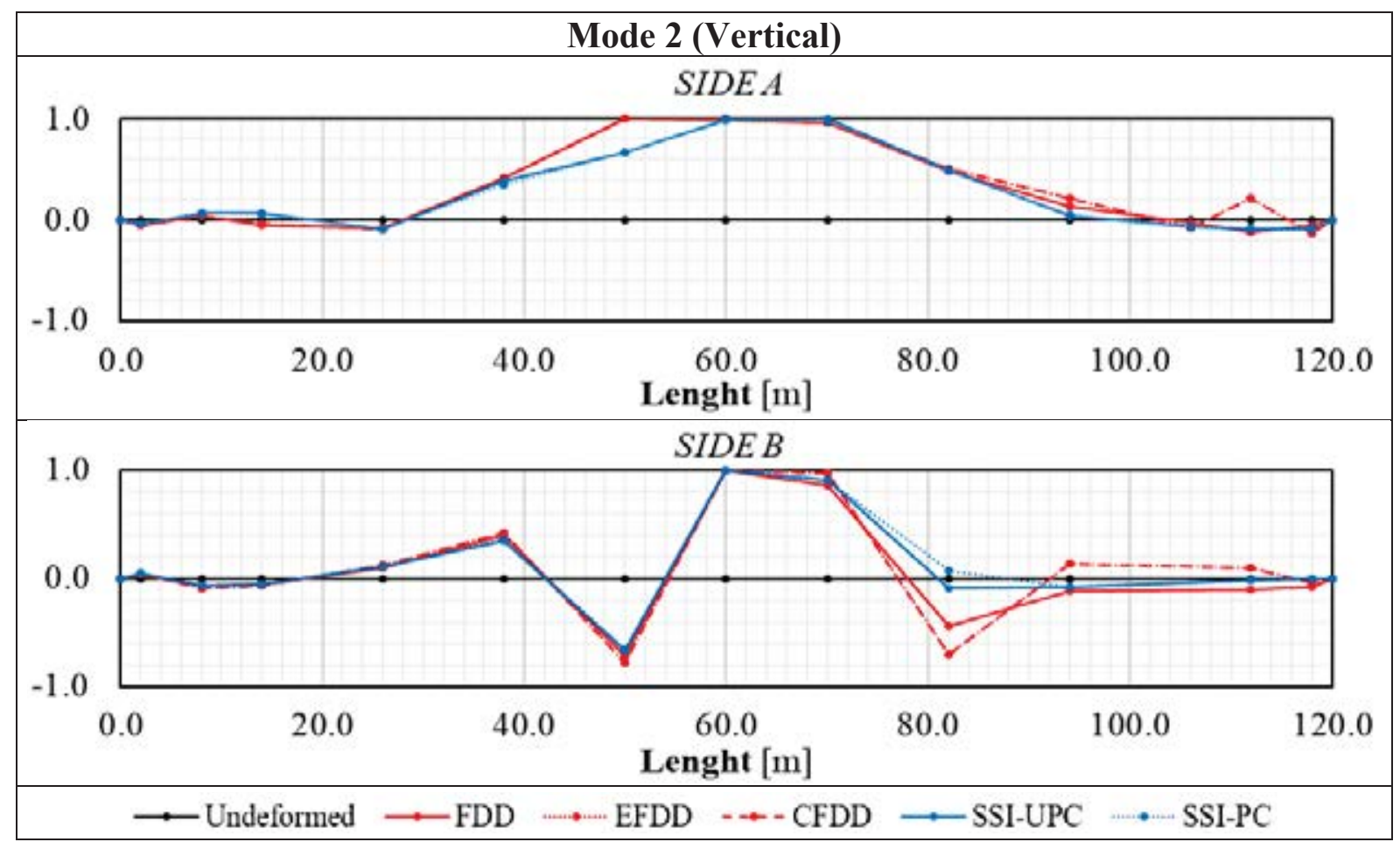

Figure 13 - Mode 2 (vertical): comparison of mode shapes obtained applying different OMA methods 
The validation of the obtained results has been carried out by the MAC number, already descript in section 2. First of all, a comparison between all the combinations of mode shape pairs calculated using a single technique is made (AutoMAC criterion). As shown in the left part of Figure 14, second and third unsynchronized mode shapes are not well-separated from each other (MAC values outside the main diagonal are about 0.5 for all techniques). After the synchronization procedure, an important improvement were obtained: the MAC values outside the main diagonal are very close to zero (right part of Figure 14) except for the SSI-PC method, where second and third modes remain very similar to each other despite the synchronization procedure.

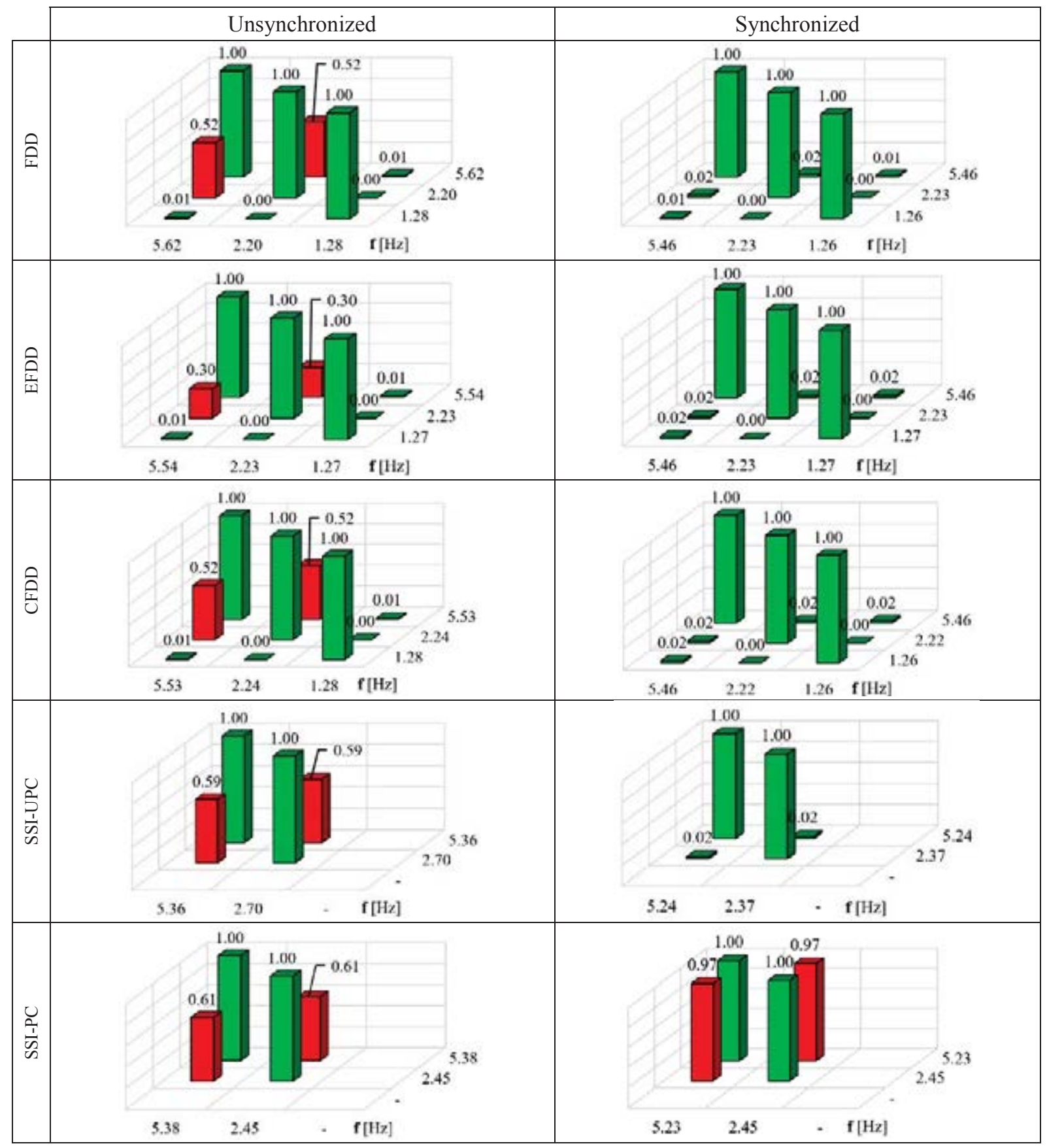

Figure 14 - Validation: comparison between MAC numbers for unsynchronized (left) and synchronized (right) mode shapes (data labels indicate the MAC numbers) 
In Figure 15 the "CrossMAC" criterion results are reported for synchronized mode shapes. It consists of comparing sets of modes calculated by different OMA techniques. High values mean a good estimation for the mode shapes. As evident, the results are good since MAC values are very high with a limited range $0.87-1.00$, except for the third mode in SSI technique (values close to 0 ).

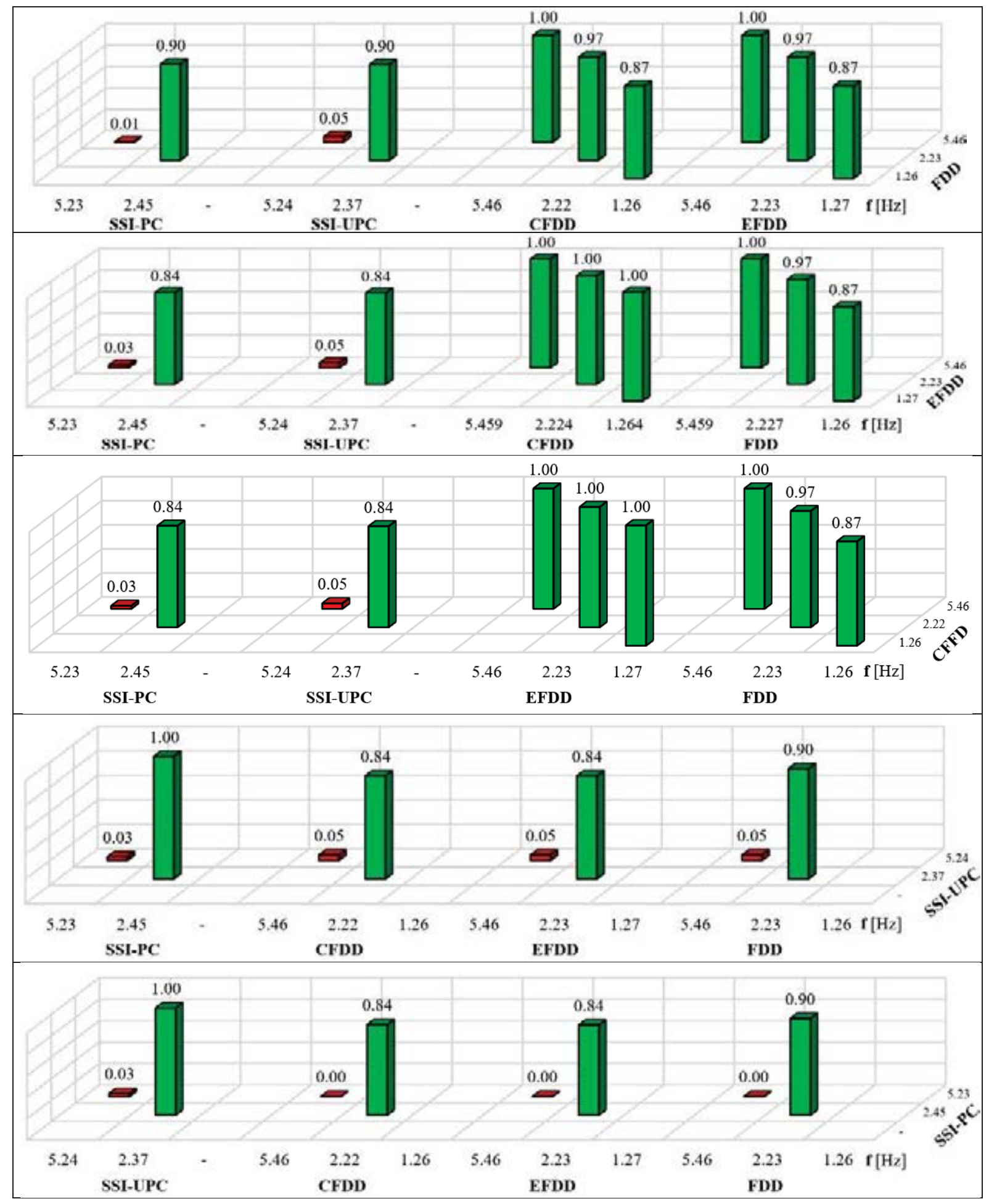

Figure 15 - Comparison between MAC numbers using different techniques for synchronized mode shapes (data labels indicate the MAC numbers) 


\section{COMPARISON BETWEEN COMMERCIAL AND PROTOTYPE EQUIPMENT TEST RESULTS}

The results of the test performed by using the prototype equipment in 2020 have been compared with those obtained on the same bridge in 2018 by using a commercial sensors equipment. In terms of frequencies, a good correlation has been found for all the OMA techniques (a difference lower than 7\% is appreciated) except for the SSI-UPC method, where an important difference of about $25 \%$ is noted for the second (vertical) mode (Table 2).

\begin{tabular}{|c|c|c|c|c|c|c|c|c|c|}
\hline \multirow{3}{*}{$\begin{array}{l}\text { OMA } \\
\text { method }\end{array}$} & \multicolumn{3}{|c|}{$\begin{array}{c}\text { Mode } 1 \\
\text { (trasversal) }\end{array}$} & \multicolumn{3}{|c|}{$\begin{array}{c}\text { Mode } 2 \\
\text { (vertical) }\end{array}$} & \multicolumn{3}{|c|}{$\begin{array}{c}\text { Mode 3 } \\
\text { (torsional) }\end{array}$} \\
\hline & $f_{\text {prototype }}$ & $\mathrm{f}_{\text {commercial }}$ & Variation & $f_{\text {prototype }}$ & $\mathrm{f}_{\text {commercial }}$ & Variation & $\mathrm{f}_{\text {prototype }}$ & $f_{\text {commercial }}$ & Variation \\
\hline & {$[\mathrm{Hz}]$} & {$[\mathrm{Hz}]$} & [\%] & {$[\mathrm{Hz}]$} & {$[\mathrm{Hz}]$} & {$[\%]$} & {$[\mathrm{Hz}]$} & {$[\mathrm{Hz}]$} & [\%] \\
\hline$F D D$ & 1.26 & 1.18 & 6.60 & 2.23 & 2.16 & 3.20 & 5.46 & 5.65 & 5.46 \\
\hline$E F D D$ & 1.27 & 1.18 & 6.93 & 2.23 & 2.12 & 5.00 & 5.46 & 5.65 & 5.46 \\
\hline$C F D D$ & 1.26 & 1.18 & 6.85 & 2.22 & 2.12 & 4.81 & 5.46 & 5.65 & 5.46 \\
\hline SSI-UPC & - & - & - & 2.37 & 1.89 & 25.44 & 5.24 & 5.65 & 5.24 \\
\hline SSI-PC & - & - & - & 2.45 & 2.32 & 5.47 & 5.23 & 5.67 & 5.23 \\
\hline Analytical result & \multicolumn{3}{|c|}{1.91} & \multicolumn{3}{|c|}{2.16} & \multicolumn{3}{|c|}{4.16} \\
\hline
\end{tabular}

Table 2 - Comparison between modal frequencies obtained by prototype and commercial equipment

A comparison between modes defined using prototype (red line) and commercial (blue line) equipment and analytical predictions (dashed blue line) is reported in Figures 16 and 17. For the first mode, except for some points, the shapes are completely overlapping (especially for the side A). For the second mode, the results are very good for the side A, while for the side B, no good result was obtained: the vectors have a direction that is opposite than expected.

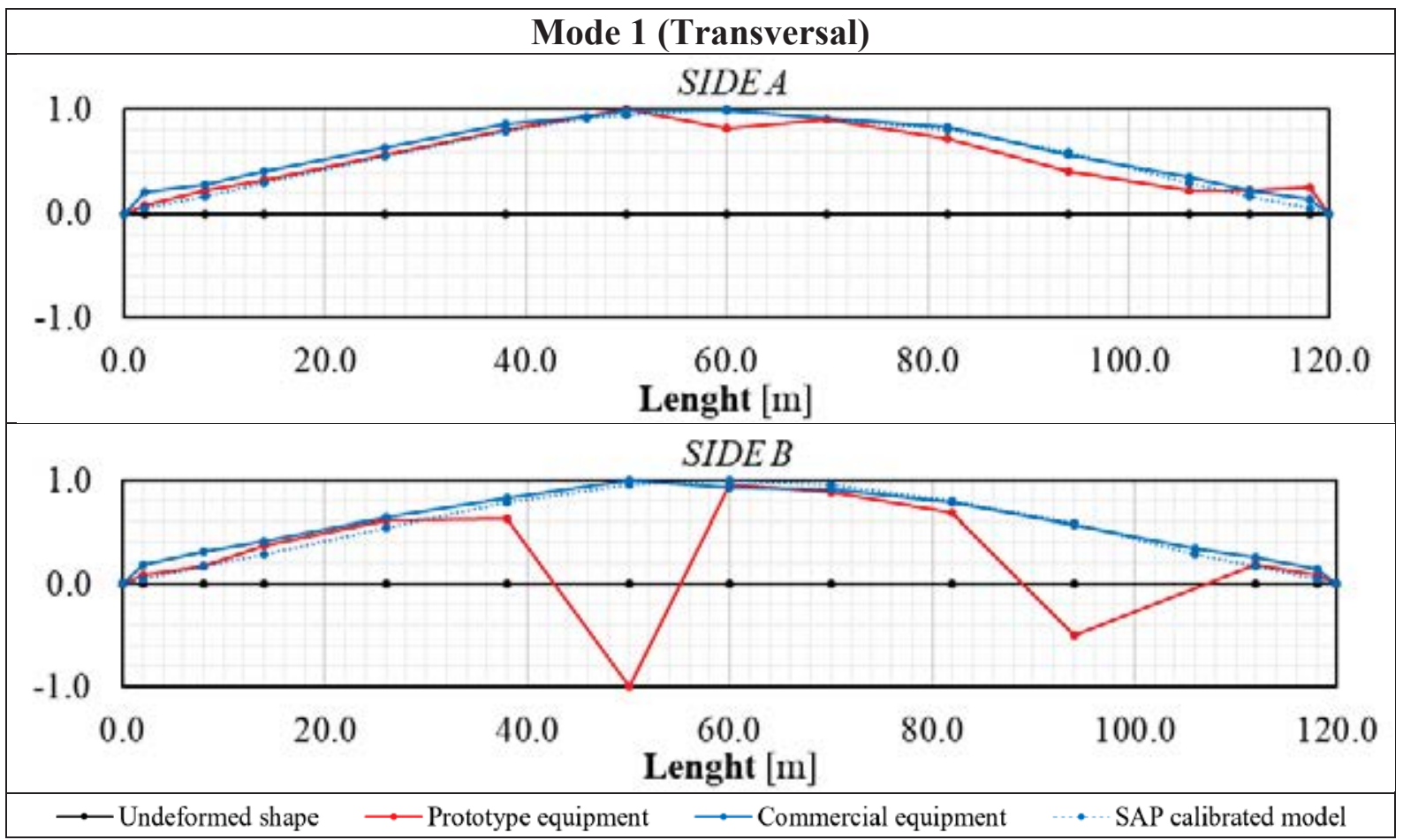

Figure 16 - Mode 1 (transversal): comparison between mode shapes defined using prototype equipment (red line), commercial sensors (blue line) and analytical calculation (dashed blue line) 


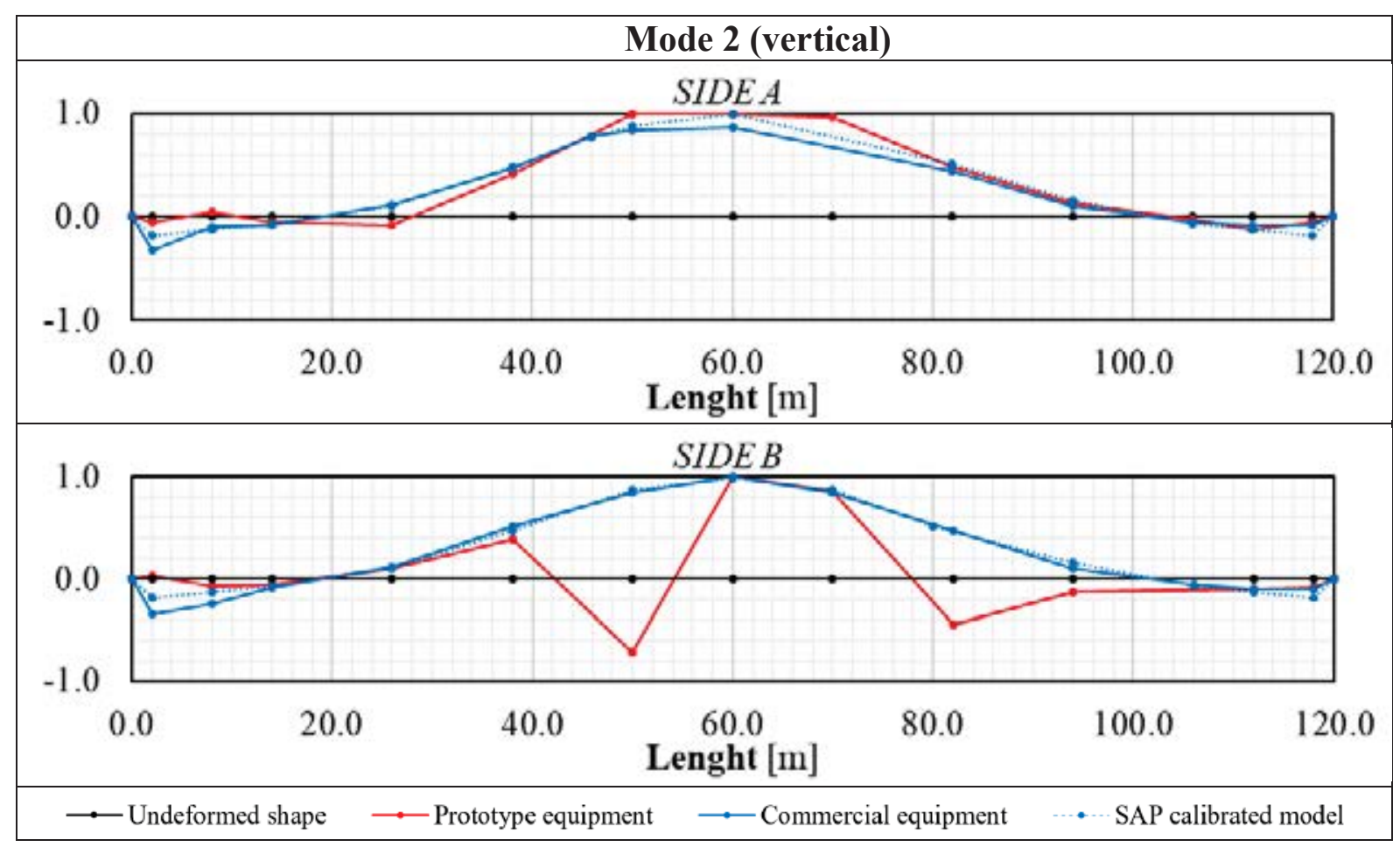

Figure 17 - Mode 2 (vertical): comparison between mode shapes defined using prototype equipment (red line), commercial sensors (blue line) and analytical calculation (dashed blue line)

\section{DISCUSSION AND CONCLUSIONS}

In this paper, the effectiveness of a wireless, low-cost and easy to install monitoring system, is evaluated. The system is a prototype consisting of nine accelerometric sensors developed by the Department of Engineering of the University of Sannio. Specific problems due to the synchronization among the devices have been addressed and solved. The equipment was tested by performing a dynamic identification test on an existing bridge located in Benevento, Italy. Two experimental mode shapes were found and validated using MAC number. The tests results have been compared with the data obtained on the same bridge in 2018 by using a commercial sensors equipment. Results demonstrate the effectiveness of the prototype system. Future developments concerning the modification of the hardware apparatus in order to solve some occurred problems have been already addressed. 


\section{REFERENCES}

[1] V. Barrile, G. Candela, A. Fotia, E. Bernardo, UAV Survey of Bridges and Viaduct: Workflow and application, ICCSA 2019 (International Conference on Computational Science and its Applications), 269-284, 2019.

[2] M. Sanchez-Silva, J. Riascos-Ochoa, Seismic risk models for aging and deteriorating buildings and civil infrastructure, Handbook of seismic risk analysis, 387-409, Doi: 10.1533/9780857098986.3.387, 2013.

[3] C.L. Page, J. Havdahl, Electrochemical monitoring of corrosion of steel in microsilica cement pastes, Materials and Structures, 18, 41-47, 1985.

[4] R.D. Browne, Mechanism of corrosion of steel in concrete in relation to design, inspection and repairs of offshore and coastal structures, ACI (American Concrete Institute) Symposium Paper, 65, 169-204, 1980.

[5] B.A. Graybeal, B.M. Phares, D.D. Rolander, M. Moor, G. Washer, Visual Inspection of Highway Bridges, Journal of Nondestructive Evaluation, Vol. 21, No. 3, September 2002.

[6] ACI 228.2R-98 (American Concrete Institute committee 228), Nondestructive test methods for evaluation of concrete in structures, Farmington Hills, Michigan, 1998, reapproved 2004.

[7] D.M. McCann, M.C. Forde, Review of NDT methods in the assessment of concrete and masonry structures, NDT\&E International Vol. 34, No. 2, 71-84, Doi: 10.1016/s09638695(00)00032-3, 2001.

[8] C. Boller, Chapter 1: Structural Health Monitoring - An Introduction and Definitions, Encyclopedia of structural health monitoring, 2009.

[9] K. Worden, C.R. Farrar, G. Manson, G. Park, The fundamental axioms of structural health monitoring, Proceedings of the Royal Society A, 463, 1639-1664, Doi: 10.1098/rspa.2007.1834, April 2007.

[10] C.R. Farrar, S.W. Doebling, D.A. Nix, Vibration-based structural damage identification, Proceedings of the Royal Society A, 359, 131-149, Doi: 10.1098/rsta.2000.0717, 2001.

[11] A. Bayraktar, T. Turker, A.C. Altunisik, Experimental frequencies and damping ratios for historical masonry arch bridges, Contruction and Building Material, 75, 234-241, 2015.

[12] A. Cabboi, C. Gentile, A. Saisi, Vibration-based SHM of a centenary bridge: a comparative study between two different automated OMA techniques, Proceedings of the $9^{\text {th }}$ International Conference on Structural Dynamic, EURODYN 2014, Porto, 2014.

[13] G.W. Chen, P. Omenzetter, S. Beskhyroun, Operational modal analysis of an eleven-span bridge subjected to weak ambient excitations, Engineering Structures, 151, 839-860, 2017.

[14] C. Ranieri, G. Fabbrocino, Operational Modal Analysis of Civil Engineering Structures An introduction and Guide for Applications, Springer, 2014.

[15] M. Ghalishooyan, A. Shooshtari, Operational Modal Analysis techniques and their theoretical and practical aspects: a comprehensive review and introduction, IOMAC15 (Internationa Operational Model Analysis Conference, May 2015), 2015.

[16] D. J. Ewins, Modal Testing: Theory and Practice, Research Studies Press, 2000. 
[17] R. Aguilar, D. Torrealva, L.F. Ramos, P.B. Lourenço, Operationa Modal Analysis Tests on Peruvian Historical Buildings: The Case Study of the $19^{\text {th }}$ Century Hotel Comercio, $15^{\text {th }}$ World Conference on Earthquake Engineering (WCEE), 2012.

[18] M. Pastor, M. Binda, T. Harcarik, Modal Assurance Criterion, Procedia Engineering, 48, 543-548, doi: 10.1016/j.proeng.2012.09.551, 2012.

[19] N-J. Jacobsen, P. Andersen, Operational Modal Analysis on Structures with Rotating Parts, ISMA International Conference on Noise and Vibration Engineering, 2008.

[20] R. Brincker, P. Andersen, Understanding Stochastic Subspace Identification, Conference Proceedings: IMACXXIV - A Conference \& Exposition on Structural Dynamics Society for Experimental Mechanics, 2006.

[21] CSiBridge 23.0.0, 1978-2016 Computers \& Structures, Inc.

[22] A. De Angelis, G. Esposito, G. Maddaloni, E. Cosenza, M.R. Pecce, Ambient vibration test on an existing prestressed concrete bridge, COMPDYN 2021.8 ${ }^{\text {th }}$ ECCOMAS Thematic Conference on Computational Methods in Structural Dynamics and Earthquake Engineering. M. Papadrakakis, M. Fragiadakis (eds.). Streamed from Athens, Greece, 27-30 June 2021.

[23] MATLAB R2020b, (C 1994-2021 The MathWorks, Inc.

[24] ARTeMIS Modal 6.0 (C) 1999-2019 Structural Vibration Solutions A/S.

[25] Sequoia, vibration monitoring: https://en.sequoia-vibrationmonitoring.com/gea-line/ 